By acceptance of this article, the publisher or recipient acknowledges the U.S. Government's right to rotain a nonexclusive, rovalty.free license in and to any copyright covering the article.

\section{$06,5-50406-65$ \\ CONF $-830406--65$}

DE83 012351

\title{
EBT REACTOR CHARACTERISTICS CONSISTENT WITH STABILITY AND POIVER BALANCE REQUIREMENTS ${ }^{*}$
}

\author{
N. A. Uckan and R. T. Santoro \\ Oak Ridge National Laboratory \\ Oak Ridge, Tennessee 37830
}

(615) $574-1354$

\section{ABSTRACT}

This paper sumnarizes the results of a recent EBr reactor study that includes both $r$ ing and core plasna properties and consistent treatment of coupled rino-core stability criteria and power balance requirements. The principal finding is that constraints imposed by these coupling and other physics and technology considerations permit a broad operating window for reactor design optimization. A number of concept improvenents are also proposed that are found to offer the potential for further improvement of the reactor size and parameters.

\section{INTRODUCTION}

Present ELM Bumpy Torus (EBT) reactor studies: differ from earlier ones primarily by including tneoretical stability criteria developed in the past several years (particularly the Le-Van Dam-Nelson (LWN) 1 imit $\left.{ }^{2}, 3\right\}$ and their coupling to the ring power requitements. The principal result is that these criteria and other physics and technology constraints permit a broad operating window for reactor optimization. Within this operating window, physics and engineering systens analysis and cost sensitivity studies indicate that reactors with $\left\langle B_{\text {core }}\right\rangle \sim 6-108, \mathrm{D} \sim 1200-1700 \mathrm{MW}(\mathrm{e})$, wi:11 loading $\sim 1.5-2.5 \mathrm{MW} / \mathrm{m}^{2}$, and recirculating power fraction (including ring sustaining power and all other reactor auxiliaries) $\sim 10-158$ are possible.

The physics rationale for this recent study includes: (1) equilibrim, particle orbits, and magnetics optimization: (2) confinement/transport scaling; (3) stability (beta limits); (4) electron and ion ring power requirgments; (5) optimal pressuce frofiles; and (6) coupling of ring and core plasma properties. In addition, the EBr systems code: has been developed to integrate physics, engineering, and cost constraints to establish a macrostable, steady-state operating vindow for a family of ZBI reactors that are competitive with other fusion reactors.

Whereas nost of the discussions are centered on stability, ring power requirements, optimal pressure profiles, and their impact on reactor operating space, consider briefly scme of the other highlights from the study. Al Also, a number of concept improvenents are introduced that could offer the potential for further improvement of the reactor parameters (such as size, recirculating power fraction, etc.).

\section{COUPLED CORE AND RING STABILITY LIMITS}

The basic EBr operation requires the use of high beta, hot electron :ings for the stability of the overall

-Researcn sponsored by the Office of Eusion Energy, U. S. Department of Energy, under contract $\$ 7405-e n g-26$ with the Union Carbide Corporation. plaswa. These rings form near contours of constant mod-B in the midplane of each mirtor section and produce a local magnetic well near the edge of a toroidally confined plastra. Typical profiles of the magnetic field, toroidal core and $\tau$ ing pressure profiles, and $U=i \mathrm{i} k / \mathrm{B}$ are shown in fig. 1.

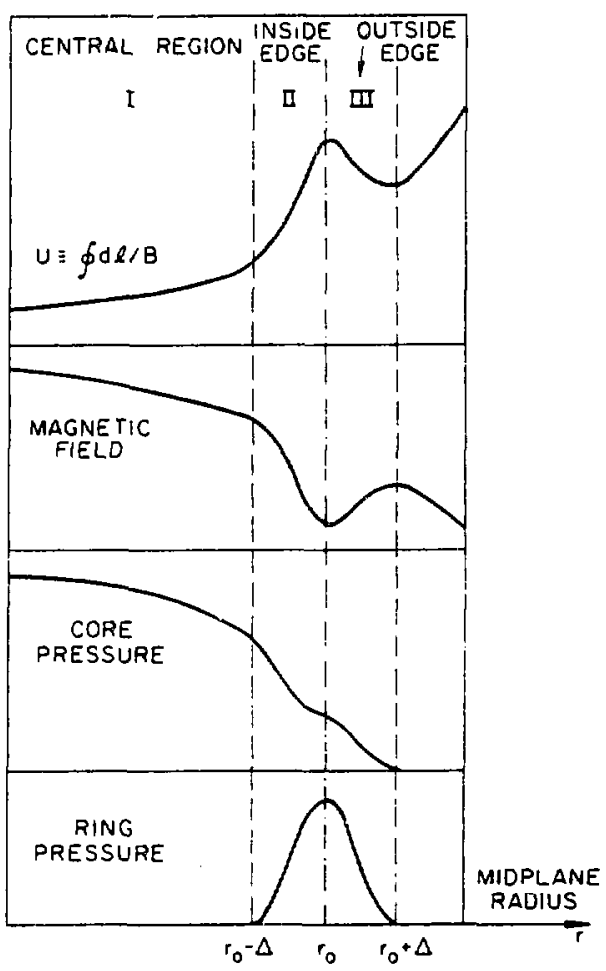

Fig. 1. Typical protiles of $U \equiv: d \mathscr{L} B$, the magnetic field $B$, and pressures (core and $r$ ing) as a function of midiplane radius.

In EBT, the stability requirenents of core and energetic $r$ ing plasmas are closely coupled, 6,5 and their interaction derines the stable operating regimes of both plasmas and determines core beta $\left(\hat{B}_{C}\right)$ limits, as well as the allowable upper and lower limits of the ratio of the core to the hot plasma densities $\left(n_{c} / n_{h}\right)$.

\section{NOTHGE}

PORTIONS OF THIS REPORT ARE ILLEGIBLE.

It has been reproduced from the best available copy to permit the broadest possible availability.

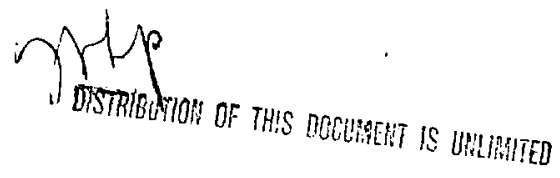


The role of high beta, hot electron tims in maintaining the stability of the toroidal core plasna against flute and interchange rodeg may be seen from Fig. 1 and the simple stability criterion given by ${ }^{6}$

$$
\{p \tau+r p U]\left[U^{4}-p^{2}\left(d / / B^{3}\right)\right]>0 .
$$

where $U=\& d 2 / B, p$ is the core plasma pressure, $Y$ is the ratio of specific heats, and the derivative is with respect to the flux $\left.\psi^{\circ}=d / d \psi\right)$. In the central region and at the inside extge of the ring (regions I and II in Fig. 1), stability is attained if $\mathrm{p}^{-}=0$ or

$$
p / p>-40 \%
$$

At the outer edge (region III), stability is possible if

$$
|p| \leq\left|0^{-1}\right| \rho d \ell / s^{3} .
$$

Thus, the electron $r$ ing modifies $B$ and $d \Omega / B$ in such $a$ way as to stably support core plastia pressure gradients in the regions in which they are largest. The stability threshold is then related to the critical value of ring beta, of,crit, necessacy to reverse the gradients it the outer euge of the plasma, which is given by

$$
\text { h,crit }=2 \mathscr{Y}\left\langle\mathrm{R}^{\rangle}\right. \text {, }
$$

where i $z$ ing half-widtli and $\left\langle R_{c}\right\rangle=$ average magnetic field radius of curvature.

Although the hot electron $r$ ings provide a local minimum in $a$ and stabilize low beta interchange modes of the toroidal core plasma, a number of instabilities (curvature-driven modes) may still persist because of electromagnetic coupling between ring and core plasmas. Among then is the core pressure-driven interchange node, which is stable if

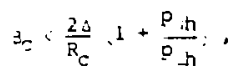

where $R_{C}$ is the lacal radius of curvature in the midplane and $p_{i n}$ and $p_{h}$ are the hot electron ring pressures parallel and perpendicular, respectively, to the $\mathrm{g}$ field. This is the core beta 1 inat $^{2}, 3^{3}$ (so-called LVN linit) near the outside edge of the core plasma isee Fig. L, region (II), which is typically on the order of 10-158 tor a reactor. Volume-averaged core beta depends on the core pressure profiles in the core olasna (regions I and II in Fig. 1).

Because the hot electron rings art localized in the region near the outside edge of the core plasma (see Fig. 1), the radial structure of the instability -1.jenrmodes is assumed to be more significant near the rings on the autside edge, and almost all of the theoretical calculations to date that are cartied out for reyiun III assume core pressure gradient $p^{\circ}=0$ in regions I and II. As will be discussed later, this assumption (made for ronvenience of calculations) is neither realistic nor Earorable for reactor applications.
Summaries of the various modes that may be relevant to a reactor and approximate analytic expressions i, 5 for their reapective stability criterla are listed in $\mathbf{T} a b i 31$.

Table 1. Sumary of stability conditions

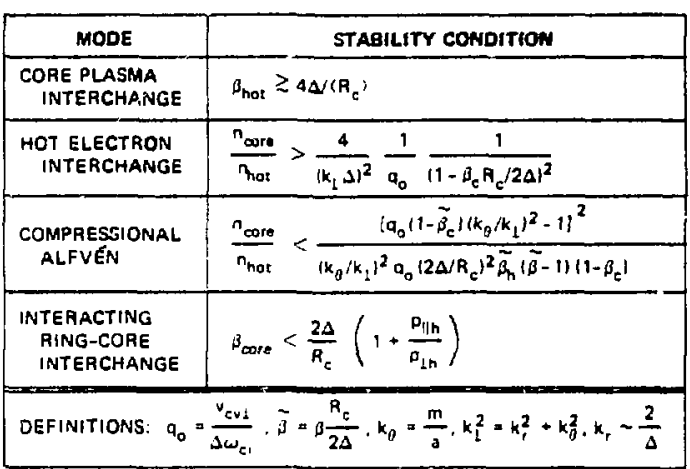

These are the core interchange, hot electron interchange, and interacting ring-core interchange (LVN) modes. The compressional Alfven does not pose any problem Eor reactor-like devices. Typically, these modes inpose restrictions on upper and laver limits of $n_{d} / n_{h}$, an upper linit on $B_{\text {c }}$ a lower linit on $B_{\text {h }}$ etc.; these restrictions are determined by $r$ ing scale length $\Delta$, radius of curvature $R_{C}$ (lucal and/or field line averaged), $q_{0}=v_{\mathrm{Cv}} / \omega_{c i} \Delta^{\Delta}$, I x ratio of curvature drift frequency to ion cyclotron irequencyl, anisotropy, radial and poloidal wave numbers. etc.

Al though core beta values on the order of 10-158 have been estinated, the coupling of beta linits with ring dimensions (through $\Delta$ ) and power balance (through $n_{c} / n_{h}$ ) is a concern for a reactor. Boundaries of a reactor plasma operating window as a function of $n_{c} / n_{h}$ and $q_{0}$ are shown in Fig. 2. Within the constraints (1) that reactor parameters lie within the possible operating window show in fig. 2 for stability and (2) that the core pressure profile inside the ring (regions I and II in Fig. 1) satisfies core interchange criteria (see next section) for profile considerations, we find that a Eavorable reactor design can be formulated in regard to both the recirculated power fraction and the total Eusion power produced.

\section{OPTIMAI. HRESSURE PROFILES}

The economic viability of an EBT reactor improves noticeably if the average core beta $\left\langle B_{\rangle}\right\rangle$significantly exceeds -53 . The radial profiles of core pressure (which, for simplicity, arn assumed to be constant in most of the stability calculations discussed in sect. I) are found to play an inportant role in both fusion and ting power balance. ! Since the magnetic fields in EBr vary both radially and axially (along the field lines), for constant pressure profiles, the rolume-averaged core beta $\langle B\rangle$ is muci smaller than the theoretically calculated core beta d. value near the outside edge of the ring (region III in Fig. 1):

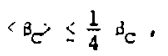

\section{DISCLAIMER}

This report was prepared as an account of work sponsored by an agency of the United States Government. Neither the United States Government nor any agency thereof, nor any of their employees, makes any warranty, express or implied, or assumes any legal liability or responsibility for the accuracy, completeness, or usefulness of any information, apparatus, product, or process disclosed, or represent:; that its use would not infringe privately owned rights. Reference herein to any specific commercial product, process, or service by trade name, trademark. manufacturer, or otherwise does not necessarily constitute or imply its endorsement, recommendation, or favoring by the United States Government or any agency thereof. The views and opinions of authors expressed herein do not necessarily state or reflect those of the United States Government or any agency thereof. 

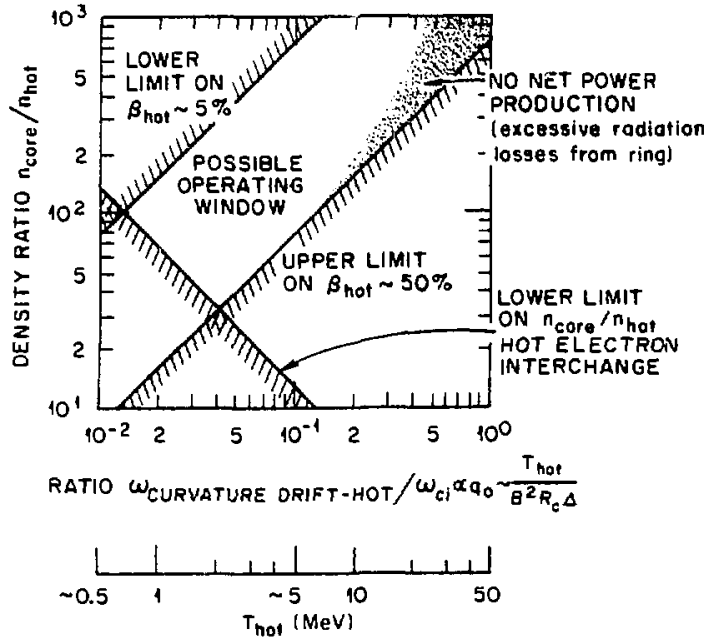

Fig. 2. Boundaries of stable operating window in $n_{\text {core }} / n_{\text {hot }}\left({ }^{n} \mathrm{c} / n_{h}\right)$ vs $q_{0}\left(T_{\text {hot }} / B^{2} R_{c} \Delta\right)$ space in a reactor. Various boundaries are indicated.

where the limit on $B$ is given by $\mathrm{Eq}$. (5). This imposes a serious cconomic penalty for a reactor. However, if pressure gradients in the core plasna (in regions I and II of Fig. 1) are allowed, $\left\langle B_{c}\right\rangle$ is found to be camparable to local core beta at the outer edge of the ring:

$$
\left\langle\mathrm{B}_{\mathrm{C}}\right\rangle=(0.5-1.0) \mathrm{B}_{\mathrm{C}} .
$$

This permits fusion power density to be high enough for a sufficiently small ting width and, in turn, an allowable recirculating power fraction for ring-sustaining power.

In the absence of detailed kinetic derivations. stable pressure profiles are derived fram the MD criterion ${ }^{6}$ given by Eq. (1) for the core plama (regions I and II in Fig. 1), there $\mathrm{FB}$ is not reversed, and from kinetically derived relations for the outer edge (region III).

In regions I and II the stability condition is given by Eq. (2), and marginal stability is achieved if

$P^{\prime} / \mathrm{p}=-Y U^{\prime} / U=-Y\left\langle\left\langle R_{B}\right\rangle\right.$,

where $U=d 2 / B, 1 /\left(R_{B}\right\rangle=U \%, U$, and

$$
U^{-}=\partial U / \partial \psi=-;(a B / \partial \psi+x / \tau) d \& / B^{2},
$$

with $k=-1 / R_{\text {g }}$ the curvature. Equilibrium relations are used in $\varepsilon q$. (乌) to calculate $\left\langle R_{B}\right\rangle$.

In region III, the corresponding expression for Eq. (8) is $p^{-} / p=-1 / \Delta$

Combining Egs. (8) and (10), the stable core pressure profile can be derived from

$$
p^{-}(r)+a(r) p(r)=0
$$

to give

$$
p(r)=c \exp \left[-\int a(r) d r\right] \text {, }
$$

where $C$ is constant and expressions for $\alpha(r)$ are given by

$$
\alpha(\tau)= \begin{cases}\frac{2 Y \tau}{\left\langle r_{0} R_{c}\left(r_{0}\right)\right\rangle}, & 0<\tau<\tau_{0}-\Delta \\ \frac{2 Y \tau}{\left\langle r_{0} R_{c}\left(r_{0}\right)\right\rangle}\left(1+\frac{\theta_{h}\left\langle R_{C}\right\rangle}{4 \Delta}\right), & r_{0}-\Delta<r<r_{0} \\ \frac{1}{\Delta}, & r_{0}<r<r_{0}+\Delta\end{cases}
$$

where the angle brackets represents fleld line average, is the ring radius, $B_{\text {is }}$ is the ring beta, and $y=5 / 3$ is the ratio of specific heats (see Fig. I Eor yeometry).

Considering, for example, the central core plasma region in Fig. $1,0<t<\varepsilon_{0}-\Delta$.

$$
p(r)=p(0) \exp \left[-Y r^{2} / r_{O} R_{C}\left(r_{O}\right)\right] .
$$

For a representative set of reactor parameters $\mid \Delta / r=0.1$ $\left.r_{\sigma} / R_{c}\left(r_{o}\right)=1 / 2-1 / 3\right)$ one Einds $p\left(r_{0}-\Delta\right) / p(0)=0.6=0.1$ and $\mathrm{p}\left(\tau_{0}\right) / \mathrm{p}(0)=0.3 \pm 0.1$. This implies that $\mathrm{e}_{\mathrm{C}}(0)=$ $(1-2) B_{c}\left(r_{0}\right)$ and $\left.\left\langle B_{C}\right\rangle \sim O \mid B_{C}\left(r_{0}\right)\right]$, where $B_{c}\left(r_{0}\right)$ is the core beta value that enters in theoretical scability calculations. It should be noted that the radial pressure profiles obtained from one-and-one-half-dimensional $(1-1 / 2-D)$ transport calculations t are found to be sinilar to those required for stability.

\section{STEADY-STATE RING POWER REQUIREMENTS}

In present $E B I$ experiments hot electron rings (formed by electron cyclotron heati, gross plagna stability. Power losses fram these hot alectron rings tr. observed to scale classically, $4,7,0$ primarily determined by drag cooling, pitch angle scattering, and synchrotron radiation. Ring temperature is observed to be linited by $o / L=5 \times 10^{-2}$ scaling, corresponding to the nonadiabatic limit (whtre $p=$ average hot electron gyroradius and $\mathrm{L}=$ magnetic field radius of curvaturel.

The use of ion rings 1,10 that could be fomed by ion cyclotron heating (ICH) is also proposed. The properties of ion rings are compared with those of electron rings to detemine the potential physics and/or technology advantages. It is found that (1) ion rings would require devices with reactor-like size and magnetic field strengths for stable, adiabatic confinement if the criterion $\alpha / L=5 \times 10^{-2} \mathrm{limits}$ the ion $\mathrm{ring}$ temperature 
(as it appears to do for hot electron rings); (2) stability conditions for curvature-driven modes (discussed in Sect. II) are the sape for ion and electron rings, although aditional diamagnetic drift and anisotropy driven modes may be present; and (3) power requirements for ion rings can be qualitatively lower than those for electron rings, provided the ion ring volune does not greatly exceed the electron ring volume.

\section{A. Electron Ring Power Losses}

The power absorbed in the ring $P_{r i n g} e$ is balanced by losses sle to drag cooling of hot electrons on core electro.2s, pitch angle scattering of the ring electrons on core icns and electrons, and synchrotron radiation. The paver loss is given (in mks units with temperature in keV and power in $([\mathrm{w})$ by 1,9

$$
P_{\text {ring,e }}(M W)=0.16 B_{h} B_{R}^{L i n g}, e^{G\left(Y, B_{h}, n_{\alpha} / n_{h}\right)} \text {, }
$$

where $v_{r i n g, e}=2 \pi a \cdot \Delta_{e} \cdot\left(N_{T}\right.$ ing $)$ is the ring volune, with $a=r_{0} \Rightarrow$ plasma radius, $s_{e} a$ electron ring halfwidth, $L_{r \text { ing }}=r$ ing length $(x a)$ and $N=$ number of $r$ ings (sectors); $B_{h}$ is the $r$ ing beta $\left(B_{h} \times m_{7} T_{h} B_{k}^{2}\right.$ with $m_{h}$ and $T_{h}$ the density and temperature of the ring); and $B_{R}$ is the magnetic field at the $r$ ing location. Here

$$
\begin{aligned}
& G\left(r, s_{h}, n_{C} / n_{h}\right)=1+2.5(r-1) \\
& +7.4 \theta_{h}\left(\frac{n_{C}}{n_{h}}\right) \frac{y /(r-1)^{2}}{\left(y^{2}-1\right)^{1 / 2}}\left(1+\frac{4}{y+1}\right) .
\end{aligned}
$$

where $\varphi=1+T_{h} / 511$ is the relativistic factor and $n_{C} / n_{h}$ 15 the ratio of the core to ring plasna density at the ting location.

\section{Ion Ring Power Losses}

Power loss fran the ion rings is found to be dominated by coulomb drag cooling of energetic ions on background core electrons, although drag and scattering by background core lons are not entirely negligible. 10 At the ion ring energies (on the order of megaelectron voles, Yev required for stable reactor operation, chargeexcnange losses have a small effect on the power balance. The total power required for ion rings can then be approximated as:0

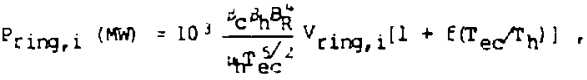

where $V_{\text {ring, } i}=2 \pi a \cdot s_{i} \cdot\left(\mathrm{NL}_{\mathrm{r}}\right.$ ing' is the fon ring volume of half-wideh $s_{i}, \mathrm{~F}_{\mathrm{ec}}$ is the core plasma electron temperature at the $r$ ing location, $i_{h}=m_{r} / m_{p}$ is the ratio of the hot ion mass to the proton mass, ${ }^{B_{c}}$ is the core beta at the ring location, and the function $f^{c}$ is small and on the order of $-10^{-}$:

\section{Comparison of Electron and Ion Rings}

The power required to sustain an ion ring ( $P_{r i n g, i} \equiv P_{i}$ ) relative to that required for an electron ring ( $\left.P_{r i n g, e} \equiv P_{e}\right)$ can be calcuiated fron Eqs. (14) and (16) to give

$$
\mathrm{P}_{\mathrm{i}} / \mathrm{P}_{\mathrm{e}}=2 \mathrm{~F}_{\mathrm{h}}^{-1} \mathrm{~B}_{\mathrm{c}}\left(10 / \mathrm{T}_{\mathrm{ec}}\right)^{5 / 2} v_{\text {ring, } \mathrm{i}} / N_{\text {ring, }} \mathrm{e}
$$

where it is assumed that ion and electron $r$ ing betas are the same $\left(\beta_{h, i}=\beta_{h, e}\right)$ with equal ring terperatures of $\mathrm{T}_{\mathrm{h}} \sim 1-2 \mathrm{MeV}$. The temperature scaling of Eq. (17) favors a large core electron temperature in the ring region. Considering comparable ion and electron ring volumes with $\mathrm{B}_{\mathrm{c}} \sim 0.1$ and $\mathrm{T}_{\mathrm{ec}} \sim 5-10 \mathrm{keV}$, one has

$$
\frac{P_{i}}{P_{e}} \sim\left\{\begin{array}{l}
0.1-0.5 \text { for } D^{+} \text {ion } r i n g \\
0.2-1.0 \text { for } \mathrm{H}^{+} \text {ion } r \text { ing }
\end{array}\right. \text {. }
$$

Thus, one seeg that ion ling power requirements can be quantitatively favorable, provided that (1) the ion ring volume is not much larger than the electron $r$ ing volume and (2) the core electron temperature is not much smaller than about $5 \mathrm{keV}$ near the vicinity of the ring. One would expect $d_{i}=o_{i}$ to de a minimm ring thickness. For ion rings of $T_{h} \sim 1-2 \mathrm{MeV}$ and $B_{R} \sim 2 \mathrm{r}, \quad \rho_{i} \sim 10 \mathrm{~cm}$ [corresponoing gyroradius for electron ting is $p_{e}<0.5 \mathrm{~cm}$ with $\Delta_{e} \sim(10-30) p_{e} j$. Thus, the ion rings must be sufficientl $y$ localized so that $\Delta_{i}$ is not much larger than $\mathrm{Pi}$.

\section{COUPLING OF STABILITY AND RING POWER BALANCE}

Limitations imposed on core beta and pressure profiles, ring scale lengths, and power balance by stability zonstraints are critical in EBR in determining the operating windows of future experiments and in assessing the desirability of a reactor.

Coupling of core beta with ring volume (through the ring thickness $\Delta$ ) and with ring power losses (through the relative core/ $r$ ing density ratio $n_{c} / n_{h}$ affects reactor power balance. Minimieing ring power requites thin ? snall o) rings whereas high beta (high fusion power density) requires thick (large $\Delta$ ) rings; this implies opposing constraints. Taking into account the various stability constraints (LVN $1 \mathrm{imit}$, etc.), profile effects, and other ohysics and technology constraints, the results of system studies ' indicate the existence of a confortable operating window with acceptable ring power losses (recirculating power Eraction) in a reactor. One such operating windo is shown in Fig. 2. Boundaries of this window are deternined from the stability constraints, microwave cutolf, beta linit, and net power production requirements.

Dor a typucal ceactor of $\sim 1500 \mathrm{MW}(\mathrm{e})$, required sustaining powers are $P_{r i n g}=50-60 \mathrm{MW}$ and $P_{r i n g} i=$ 5-6 MW. Here, $\mathrm{T}_{\mathrm{h}} \sim 2 \mathrm{MeV}, \mathrm{B}_{\mathrm{h}} \sim 0.15, \mathrm{~B}_{\mathrm{c}} \sim 0.1, \mathrm{~B}_{\mathrm{h}}-2 \mathrm{~T}$, the average plasma cadius (a) $-1.5 \mathrm{~m}$, and the average core plasma temperature $\left.\left\langle T_{e c}\right\rangle=T_{i c}\right\rangle=25 \mathrm{kev}$. (Note that the core plasma termerature near the ring location 
depends on profiles; it is coughly one-half to one-third of the central value.) For this reactor case, the difference in cost of electricity is about 8-128 (in favor of ion rings) depending on the absorption efficiencies of ECH (for electron rings) and ICH (for ion rings).

\section{MAGNETICS}

The spatial position of hot electron rings (formad near contours of constant $|g|$ in the midplane) is critical to efficient utilizacion of the magnetic volume within the vacuum chamber because it determines the boundary of the toroidally confined core plagma. Recent studies li, indicate that centering of mod-B (centering of ring) through symetrizing (SYM) or inverse D (ID) magnetic configurations cari be more efficient than $\infty$ il configurations assumed in previous studies [i.e. axis-encircling aspect ratio enhancement (ARE) coils ${ }^{12}$.

one of the critical paraneters in the assessment of any $\mathrm{EBI}$ reactor magnetics configuration is the radial digtance $\Delta r=\delta$ between the first wall and the mirror coil winding with $\delta$ t tlanket and shield thickness plus various gaps, dewar, etc., under the coil. Typically, $\delta=1.0-1.5 \mathrm{~m}$ for adequate shielding and tritium breeding and $\delta / r_{\text {coil }}=1 / 3$ to $1 / 2$ for a reactor in comparison to $\delta / r_{\text {coil }} J \mathrm{~L} / \mathrm{B}$ in the present experiments (where $r_{\text {coil }}$ is the mean coil radius). A primary consideration is to

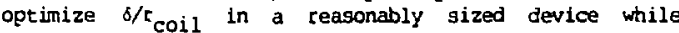
nodifying the vacuum magnetic flelds to improve singleparticle confinement and centerim of mod-B either with supplementary (i.e., SYM) coils or with noncircular (i.e.. ID) coils.

Owen and Uckan 12 have shown that the use of $5 \mathrm{Mm}$ coils, with circular mirror ovils and with $\delta=1.5 \mathrm{~m}$. resulted in a magnetic field geometry within the reactor chamber in which the midplane mod-B was symuetric across the minor axis at the ring location. The corresponding magnetic ARE factors were approximately 2 (1.5) for trapoed (passing) particles. Similar results were abtained with axis-encircling ARo coils. Both ARE and SYM coils improve volume utilization and single-particle confinement by lengthening the magnetic field lines inside the torus relative to those outside, with SYM coils being more efficient in terms of magnetic field utilization in a reactor.
Reactor applications of noncircular ID coils have also been examined. '.1! The parameters describing the noncircularity are similar to those of typical tokanak D-shaped toroidal field (TF) coils. In a bump torus, however, the vertical "straight" leg is optimally located on the outside of the torus rather than on the inside;
that is, the coil is reversed from the tokarak configuration. In a toroidal array of these coils, this orientation results in a partial cancellation of the vertical drift that arises fron the toroidicity. A finite aspect ratio torus with ID coils has a rod-B in the midplane almost perfectly sfmmetric about the magnetic axis.

The ratio of the area of the largest confined passing particle $\left(V_{3}=\mathrm{V}\right.$ drift orbit to that for trapocol particles $\left(V_{3}=0\right)$ is compared in Fig. 3 for ID coils and for circular mircor coils (with and without SYM coils) as a function of 5 for various reactor sizes. In all cases, ID coils are superior to simple circular coils. However, for $\delta \geq 1.0-1.2$ in in the example shown in Fig. 3, the improvement obtained with ID coils is mt as large as that obtained with SYM coils. With nonuniform distribution of blanket and shield thickness under and between the coils, if future detailed engineering and neutronics calculations indicate that $\delta \leq 1.0-1.2 \mathrm{~m}$ gives adequate neutcon shielding and a minimal breeding ratio under the coil then ID coils will certainly compare favorably with systens utilizing SYM coils. The ID coil magnetics system is significantly less complicated; nence, assenbly, maintenance, and access should not be adversely affected, as they are with configurations in which there are two supplementary coils per sector. Configurations with noncircular tori (squire, racetrack, etc.) are also under consideration.

\section{CONFINEMENT SCALING}

The operating parameter space of a reactor is investigated by using both time-dependent rero-ditensional $(0-D)$ and $1-1 / 2 \rightarrow D$ transport calculations. 1,13 the $0-D$ model is used for parametric burn studies to examine the global plasma performance and the sensitivity of these performance parameters to various transport assumptions and operational scenarios. The $1-1 / 2-D$ radial transport code, on the other hand, is used for determination of density, temperature, and ambipolar potential profiles and the effect of these profiles in energy confinement scaling.

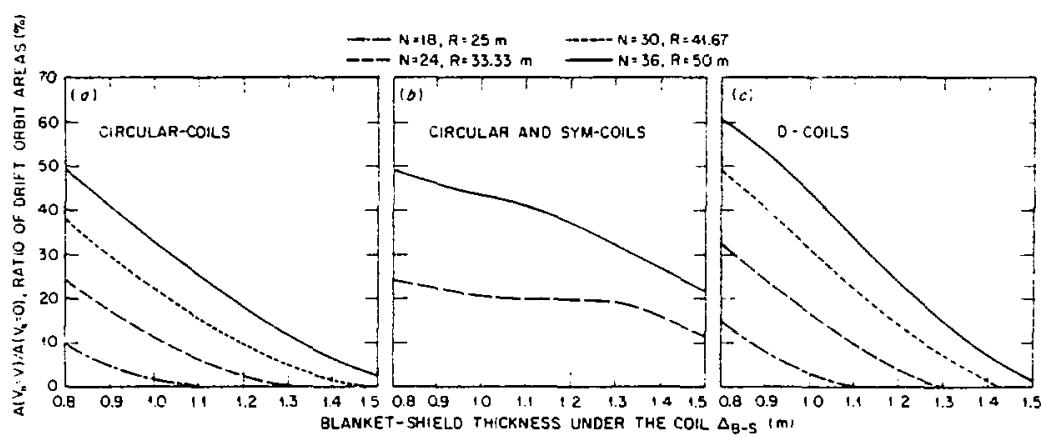

Fig. 3. The catio of the area of the largest confined passing particle $\left(v_{j}=v\right)$ arift orbit to that for trapped $\left(v_{*} \times 0\right)$ particles is shown for circular coils [without (a) and with (b) SYM colls] and for ID coils (c) as a function of blanket-shield thickness $\left(\Delta_{-s}=\delta\right)$ under the coils for various reactor sizes. 
In EBP, a simple neoclassical electron transport scaling is given by

$$
n T \sim A T^{3 / 2}\left(1+\frac{R_{B}}{R_{E}} \frac{e p}{T_{e}}\right)^{2} E \text { (profiles) }
$$

where $A=R_{T} / R_{B}$ is the magnetic aspect ratio; $R_{T}, R_{B}$, and $R_{E}$ are the major radius of the torug, magnetic field scale length, and electric field scale length, respectively; and e $\phi$ is the ambipolar potential. Because the neoclassical electron losses doninate the experimental behavior, it is difficult to make comparisons between the theoretical ion Iosses and experimental observations. Scaling laws governing ion behavior are intortant in a reactor. At present, ion lcazsport principally detemines the radial electric field $\left(E=\nabla_{4}\right)$ needed to maintain ambipolarity. $E_{r}<0$ in the experiments; however, $E_{r}>0$ is also possible, which could yield to enhanced confinement.

In a global analysis with $E_{0}<0$ [wich leads to the simple scaling given by $E q .\{19)]$, it is observed that large devices $(A>20)$ are required for ignition. Analysis with the $1-1 / 2-D$ transport simulatinn code, however, provides an important new insight into confinement scaling of EET in going from present experiments ( $\mathrm{FBT}-\mathrm{S})$ to a reactor $(\mathrm{EST}-\mathrm{R})$. It is observed that in the EBT-S to EBT-R secuence profile effects near the outer edge of the hot electron ring lead to enhanced confinement beyond the simple scaling obtained fram the global analysis (which onits these profile effects). In Fig. A the dashed curves represent the values of $n$ r calculated fron $\mathrm{Eq}$. (19) $\mathrm{fc}$. the secuence of EBT devices: $E B C-5,-P,-Q$, and $-R$. The solid curves show the results of $1-1 / 2-D$ transport simulations (for $E<0$ ) of these increasingly larger devices. Note that the confinement is better than predicted by the simple $A^{2}{ }^{3 / 2}$ scaling of Eq. (19). Profile effects suggest that confinement exceeds the simple scaling by at least a factor of $3-5$. A similar enhancenent factor is also observed as possible with $E_{r}>0$.

\section{SYSTEMS INTEGRATION}

The F.BT systens code ${ }^{i}$ is used to carry out parametric studies. Considered in this code are the coupling of the ring and core plasma properties, the consiscent treatment of the stability and wwer balance requirements, and preliminacy cost calculations. A reactor operating space obtained from the systens code is similar to one shown in Fig. 2 . Within this operating window, a representative set of reactor parameters, though not optimized, is given in Table 2 .

Table 2. Representative $E 8 \mathrm{r}$ reactor parameters

Thermal powe.

vet electric power

with electron ring $1550 \mathrm{MW}(\mathrm{e}$

with ion ring

Major radius

Average plasma radius

Number of sectors

Averaye magnetic field

veutron wall loading

Average tore density

Average core temperature

core/ring beta

Ring temperature

Ring power losses

Electron ring

Ion ring
$1650 \mathrm{MW}(\mathrm{e})$

$5000 \operatorname{MW}(t)$

$38 \mathrm{~m}$

$1.5 \mathrm{~m}$

$34 \mathrm{~T}$

$1.4 \mathrm{MW} / \mathrm{m}^{2}$

$8 \times 10^{19} \mathrm{~m}^{-3}$

$25 \mathrm{keV}$

$108 / 158$

$2 \mathrm{MeV}$

$50 \mathrm{NW}$

$5 \mathrm{M}$

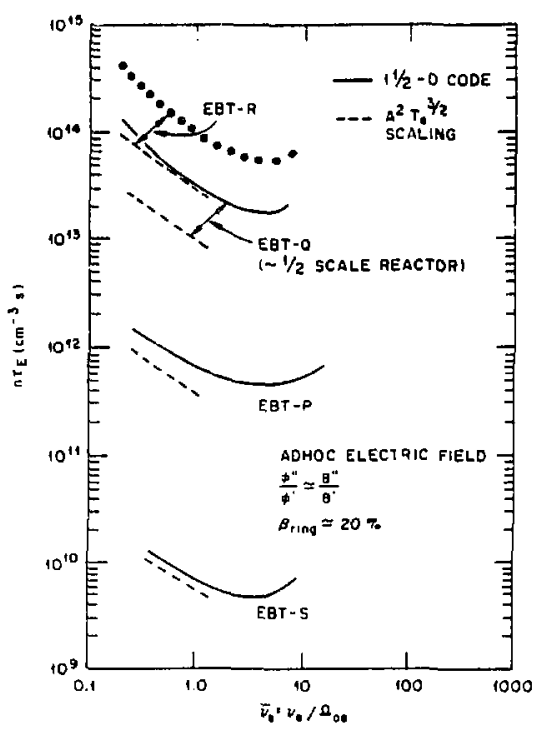

Fig. 4. Confinement parameter $\mathrm{nt}_{\mathrm{g}}$ vs collisionality $v_{e}=v^{\prime} /$ oe Eor sequence of EBr devices. Dashed curves represent values of $n \tau$ calculated from Eq. (19) Solid curves (solid circles) are results from $1-1 / 2 \rightarrow 0$ transport calculations.

REFERENCES

1. N. A. UCKAN et al., OKNL TH-8712, Jak Ridge National Laboratory (1983).

2. J. W. VAN DAM and Y. C. LEE, EET Ring Physics, Proceedings of the Horkshop, Dak Ridjge National Laboratory $(1 \overline{980})$, p. 471 .

3. D. B. NELSON, Phys. Fluids, 23, 1850 (1980) .

4. N. A, UCKAN, ed. EET Rica Physics: Procedings of Workshop, Dak Rijge, Tenn. (19B0), papers published therein; EBr Stability Theory: Proceedings of wor shop, Dak Ridge, Tenn. (1981), papers published therein; Hot Electron Ring Physics: Proceedings 2nd Horkshop, Vols. I and II, San Ditgo, Calif. (1981), papers published therein.

5. H. L. BERK et al. , Phys. Fluids, 26, 201 (1983).

6. D. G. NELSON and C. L. HEDRICK, Nucl. Eusion, 19, 283 (1979).

7. N. A. UCKAN et al., in Plasma Physics and Controlled Nuclear Fusion Research 1980, Vol. I, IAEA, Vienna (1981) P. 831

6. N. A. UCKAN and EBr Group, Plasma Phys., 25, 129 (19B3) .

9. N. A. UCKAN, Phys. Fluids, 25, 23B (1982).

10. J. B. MCBRIDE, N. A. UCKAN, and R. J. KASHUBA, nAssessment of Energetic Ion Rings Versus Electron Rings for an EEr Reactor," these proceedings.

11. L. W. OWEN and N. A. UCKAN, "Particle Confinement in EBT Peactors with Norxircular Mirror Coils," these proceedings.

12. L. W. OWEN and N. A. UCKAN, J. Eusion Energy, 1, 341 (1981)

i3. T. UCKAN, E. F. JAEGER, and N. A. UCKAN, Mransport Scaling Studies for EET Reactre." these proceedings.

14. L. A. BERRY, C. L. HEDRIC, and N. A. UCKAN, ORNL/CM-6743, Dak Ridge National Laboratory (1979). 